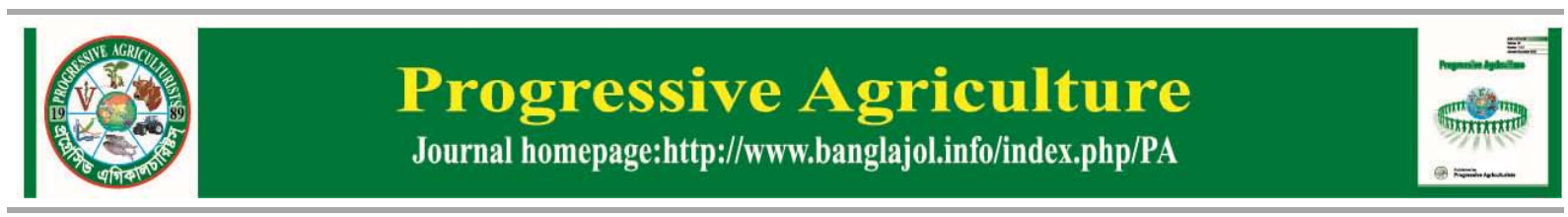

\title{
Environmental impact assessment on frequency of pesticide use during vegetable production
}

\author{
MA Islam*, MT Hossain, M Khatun, MS Hossen \\ Department of Environmental Science, Faculty of Agriculture, Bangladesh Agricultural University, \\ Mymensingh-2202, Bangladesh
}

\begin{abstract}
An investigation was carried out to study frequency of pesticide use during vegetable production and its impact on environment. A structured questionnaire and researcher's observation were used for this study. The data were collected from six different villages of sixty farmers at Mymensingh sadar upazilla in Bangladesh during February to May, 2013. More than half of the respondents (51.7\%) were illiterate and lack of knowledge on pesticide use. About $60 \%$ respondents had $16-20$ years farming experience and showed comparative knowledge on pesticide use. About 56.7\% respondents practiced monthly communication with extension worker (Block Supervisor). About 66.7\% respondents spent 04-06 hours to media every day. Half of the respondents had low level knowledge on pesticide use, where only 3.3\% respondent showed high level knowledge on pesticide use. About half of the respondents (51.7\%) used pesticide 16-20 times during the season. About 21.7\% respondent used pesticide 21-25 times during the season. For selective vegetable okra showed highest frequency, about $16.7 \%$ respondents used pesticide 26-30 times during the season, while one third respondents (33.3\%) used pesticide 16-20 times. About 58.3\% respondent used pesticide 16-20 times for brinjal, while 8.3\% respondents used 21-25 times. About two- fifth respondents (41.7\%) used pesticide 16-20 times and 21-25 times for bitter gourd, while 8.3\% respondents used 05-10 times and 10-15 times. About 58.3\% respondent used pesticide 16-20 times for snake gourd, while $16.3 \%$ respondents used $21-25$ times. About $66.7 \%$ respondent used pesticide $16-20$ times for cucumber, while 16.7\% respondents used 21-25 times. It indicated farmers used pesticide to their field 1-2 times in a week during the season in some vegetable cultivation. Therefore it has a high chance of remaining pesticide residues in the vegetables and soil. Moreover, most of the respondents applied pesticides without any protection measure and faced health problem due to expose with pesticide. Routine research work with wide public awareness, government and NGO participation, and government regulation are needed for food safety and sound environment.
\end{abstract}

Key words: Pesticide, environment, vegetable cultivation

Progressive Agriculturists. All rights reserve

*Corresponding Author: maislam@bau.edu.bd

\section{Introduction}

Vegetable cultivation is one the most economically important and dynamic branch of agriculture. It's an important group of crops and they constitute a major part of the diet contributing nutrients and vitamins. It has become an important source of income for both farmers and field laborers, serving as a vehicle for reducing poverty in rural areas. It provides more return than other field crops. Vegetables give 350\% higher monthly net return than rice (Hasan, 2005). In the year of 2008-09, 2009-10, 2010-11 vegetables were cultivated 881000 acres, 885000 acres, and 908000 acres land area respectively (BBS, 2012). At 
the same time, vegetable cultivation is becoming more costly due to the increased use of purchased inputs, such as pesticides and fertilizers, to sustain production levels. In Bangladesh, the use of pesticides, which was on average 3,850 metric tons annually during 1973-1990, has gradually increased to a record use of 37,712 metric tons in 2008 (BBS, 2008).Pesticide poisoning is a major global health problem, and it is more prevalent in countries like Bangladesh. The harmful effects on human beings in the form of acute and chronic toxicity exposed to insecticides are well established. The incidence of pesticides poisoning is increasing, and it is estimated that about 5 million people die every year as a result of intentional, accidental and occupational exposure worldwide (Singh and Gupta, 2009). Vegetables were often grown close to the household, thus creating the potential for exposure of women and children. Vegetable plots were also often located next to waterways or ponds to facilitate irrigation, thus creating the potential for contamination. Finally, vegetables tend to be sprayed heavily up to the time of harvest, and then shipped directly to market with no waiting period; moreover, many are consumed whole. These create a very significant potential for pesticide residues causing negative health effects on consumers (Dasgupta et al., 2006). Pesticides cause acute and chronic human health effects, contamination of atmospheric, ground and surface water (Howard et al., 1991; Mullen, 1995; Matthews, 2006). Most of the farmers do not concern about pesticide impact on environment. Farmer field school (FFS) farmers, $100 \%$ had high awareness on environmental pollution due to use of pesticide. In case of non FFS farmers, $66.67 \%$ had poor awareness, while $30 \%$ had medium and $3.33 \%$ had high awareness on environmental pollution (Hanif, 2000). Majority of the farmers (63\%) have moderately favorable perception on the adverse effects of agro chemical on environment, where 22\% and $15 \%$ farmers have slightly favorable and favorable perception respectively, they used pesticide abruptly (Hossain, 1999). In Bangladesh many government and non-government organization are working in the field of agriculture. Several works have done on pesticide use impact on environment during vegetable production. In our study an attempt is taken to make a document on the frequency of pesticides use during vegetable cultivation at farmer's level in Mymensingh sadar region and its impact on environment. The overall objectives of the research work were to assess the frequency of pesticide in different vegetables and to evaluate knowledge on pesticides and its effect on environment.

\section{Materials and Methods}

The study was conducted among the sixty (60) farmers of Mymensigh sadar upazilla at six (06) different villages e.g. Shambhuganj, Sheshmore, Sutiakhali, Uzan Khasiar Char, Char Nilakshmia, and Bot-tola. A list of farmer of the study area was prepared with the help of the local block supervisors, and local leaders. Sixty (60) farmers of six (06) different villages constituted the population of this study. Ten (10) farmers were selected from each village. Keeping the objective of the study in mind a structure of a questionnaire was carefully designed for collecting data. The instability prepared interview schedule was pre- tested among 05 responded of the study area which help to identify faulty and ambiguous question, correction, alteration, addition, and adjustment were done in the schedule on the basis of pre-tested result.

Data were collected through the prepared questionnaire during the vegetable cultivation season (February-May). All of the collected data were checked and cross checked before transferring to the master table sheets. For this study the collected data were coded, compiled tabulated and analyzed in accordance with the objective. Qualitative data were converted into quantitative by means of suitable scoring technique wherever applicable. Statistical measurements such as number and percent distribution of the variables will be done with the Microsoft Office Excel 2007. The tables were also used in presenting data for clarify of understanding.

\section{Results and Discussion}

Age: The age of the farmers ranged from 31-60 years with the mean 45.55 years. The farmers were categorized on the basis of their age which is present 
in Table 1.The highest proportion (36.7\%) of respondents fell in the 36-40 years aged category, while $28.3 \%$ respondents were fell in the 31-35 years aged category, $15.0 \%$ respondent were fell in the 41 45 years aged category, $10 \%$ respondents were fell in the 31-35 years aged category, 6.7\% respondents were fell in the 51-55 years aged category, and the lowest proportion (3.3\%) of respondents fell in the 56-60 years aged category (Table 1). Sutradhar (2002) reported that there was a positive insignificant relationship between age of the respondent and there awareness on environmental degradation.

Table 1. Distribution of respondents based on the age

\begin{tabular}{ccc}
\hline Age Level & Frequency & Percent \\
\hline $31-35$ & 17 & 28.3 \\
$36-40$ & 22 & 36.7 \\
$41-45$ & 9 & 15.0 \\
$46-50$ & 6 & 10.0 \\
$51-55$ & 4 & 6.7 \\
$56-60$ & 2 & 3.3 \\
\hline
\end{tabular}

Educational qualification: The education of the farmers ranged from Illiterate to Higher education. The farmers were categorized on the basis of their education. The highest proportion (51.7\%) of respondents had no level of education knowledge. They were illiterate, while $35.0 \%$ of respondents had primary level of education. About $11.7 \%$ respondents had Secondary level of education, and only $1.7 \%$ respondents were higher educated. Education change human behavior. It helps an individual to be aware of his environment for solving various problems. Hanif (2000) reported that educated farmers were more careful on pesticide use and its impact on environment.

Farm size: Farm size varies from person to person and farm size was recorded as local unit katha in the study area. The highest proportion (48.3\%) of respondents had minimum farm size 06-10 katha, while $41.7 \%$ respondents were under $11-15$ katha farm size, 8.3\% respondents were under 16-20 katha farm size, and lowest proportion of respondent (1.7\%) had 21-25 katha farm.
Farming experience: This research study showed that the highest proportion (60.0\%) of respondents had 16-20 years farming experience, while $23.3 \%$ of respondents had 10-15 years farming experience, $6.7 \%$ of respondents had 21-25 years farming experience, $6.7 \%$ of respondents had 25-26 years farming experience, and only $3.3 \%$ of respondents had 36-40 years farming experience. Islam et al. (1998) showed experienced farmers had more agricultural knowledge and more aware about pesticide impact on environment. But this research showed more experienced person had lower level of knowledge of pesticide use.

Knowledge level of pesticide use: The knowledge of using pesticide makes the farmer aware on environment and helps them to reduce pesticide use. This research showed the highest proportion (50\%) respondents had low level knowledge on pesticide use, while $46.7 \%$ respondents had medium level knowledge on pesticide use. Only 3.3\% respondents gathered high level knowledge on pesticide use. According to Sarker (1999), farmers' knowledge on the use of agro-chemicals increases their perception on environmental degradation. Another study by (Sutradhar, 2002) found there was a positive significant relationship between knowledge of the respondent and their awareness on environmental degradation.

Pesticide use frequency in a season: Pesticide use frequency ranged from 5-30 times in a season with mean 3.0169 times and standard deviation 0.97364. The farmers were categorized on the basis of their pesticide use frequency in a season which is present in Table 2.

Table 2. Distribution of respondents by pesticide use frequency in a season (February to May)

\begin{tabular}{ccc}
\hline Pesticide Frequency & Frequency & Percent \\
\hline $5-10$ & 7 & 11.7 \\
$11-15$ & 2 & 11.7 \\
$16-20$ & 31 & 51.7 \\
$21-25$ & 13 & 21.7 \\
$26-30$ & 2 & 3.3 \\
\hline
\end{tabular}


The highest proportion (51.7\%) of the respondents were used pesticide 16-20 times during the season, while $21.7 \%$ of the respondents were used pesticide 21-25 times, $11.7 \%$ of the respondents were used pesticide 5-10 times and 11-15 times, and 3.3\% of the respondents were used pesticide a great proportion 26-30 times during the season (Table 2).

Farming experience with knowledge level of pesticide use: The knowledge level of pesticide use of the respondents categorized with farming experience ranged from 10-40. Based on the farming experience with knowledge level of pesticide use cross tabulation are given bellow (Table 3).

Table 3. Distribution of respondents based on the farming experience with knowledge level of pesticide use

\begin{tabular}{|c|c|c|c|c|}
\hline \multirow{2}{*}{$\begin{array}{c}\text { Farming } \\
\text { experience } \\
\text { (years) }\end{array}$} & \multicolumn{3}{|c|}{$\begin{array}{c}\text { \% of knowledge } \\
\text { level of pesticide use }\end{array}$} & \multirow{2}{*}{$\begin{array}{c}\text { Total } \\
\text { respondent } \\
\text { percentage }\end{array}$} \\
\hline & $11-15$ & $16-20$ & $21-25$ & \\
\hline $10-15$ & 26.7 & 17.9 & 50.0 & 23.3 \\
\hline $16-20$ & 66.7 & 57.1 & 0 & 60.0 \\
\hline $21-25$ & 0 & 14.3 & 0 & 6.7 \\
\hline $26-30$ & 3.3 & 7.1 & 50.0 & 6.7 \\
\hline $31-35$ & 0 & 0 & 0 & 0 \\
\hline $36-40$ & 3.3 & 3.6 & 0 & 3.3 \\
\hline
\end{tabular}

Data furnished the table show that highest proportion of knowledge level of pesticide use respondents (59.3\%) had 16-20 years farming experience. While 23.7\% responded knowledge level of pesticide use had 10-15 years farming experience, $6.8 \%$ respondents' knowledge level of pesticide use had 21-25 and 26-30 years farming experience, 3.4\% responded knowledge level of pesticide use had 3640 years farming experience (Table 3). Islam et al. (1998) showed experienced farmers had more agricultural knowledge and more aware about pesticide impact on environment. But this research showed more experienced person had lower level of knowledge of pesticide use.

Crop based pesticide frequency in a season: Farmers of different area usually use pesticide to their field haphazardly without thinking of environmental effect. The highest proportion 58.3\% respondent had use pesticide 16-20 times in a season for brinjal, while $25 \%$ respondents had use pesticide 11-15 times, 8.3\% respondents had use pesticide 510 times and 21-25 times (Fig. 1 a). About one third (1/3) respondents had use pesticide 16-20 times in a season for okra, while one fourth (1/4) respondents had use pesticide 21-25 times, one sixth (1/6) respondents had use pesticide 5-10 times and 26-30 times, one twelve (1/12) respondents had use pesticide 11-15 times (Fig. 1 b).About two fifth (2/5) of the respondent had use pesticide 16-20and 21-25 times in a season for bitter gourd, while one twelve (1/12) of the respondents had use pesticide 5-10 and 11-15 times (Fig. 1 c).The highest proportion 58.3\% respondent had use pesticide 16-20 times in a season for snake gourd, while $16.7 \%$ respondents had use pesticide 5-10 times and 21-25 times, 8.3\% respondents had use pesticide 11-15 times (Fig. 1 d).About $66.7 \%$ respondent had use pesticide $16-20$ times in a season for cucumber, while $16.7 \%$ respondents had use pesticide 21-25 times, 8.3\% respondent had use pesticide 5-10 times and 11-15 times (Fig. 1 e).

\section{Conclusion}

Bangladesh is an over populated and agro based country. Use of pesticide in agriculture has been increasing day by day in order to get increasing agriculture production. The farmers of this country are increasingly using these pesticides in their farming without considering its long run effect, either knowingly or unknowingly. For the better living in better environment having knowledge on pesticide use and its impact on environment are very important. There were no beneficial insects, frogs, snail found in the study areas. Some claimed about aquatic life hampered due to use of pesticides. Most of the respondents were not take any protection measure during pesticide application. A few claimed that they faced some problems like- vomiting, irritation on skin, headache, and eyesight problem. The finding of this research would be helpful to different organizations for planning, implementation, and evaluation of programme related to ongoing high 
extent impute based agriculture and environment issues.
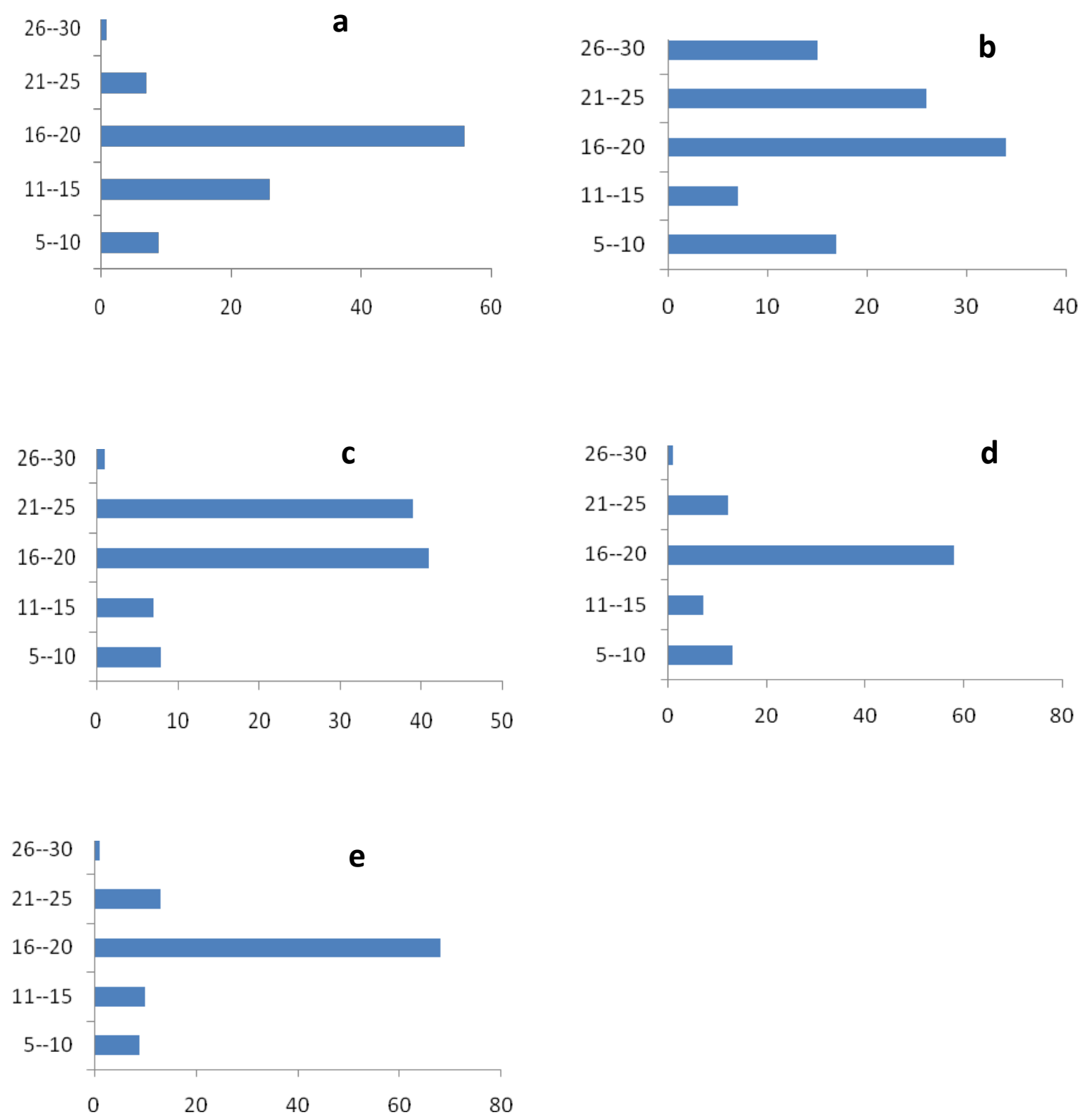

Figure1. Pesticide use frequency in different crops during February-May in the study areas. Figures in parenthesis indicate different crops, like (a) Brinjal; (b) Okra; (c) Bitter gourd; (d) Snake gourd; (e) Cucumber. X axis denotes the percentage of respondents and $\mathrm{Y}$ axis denotes the different age groups of respondents

\section{References}

BBS (Bangladesh Bureau of Statistics) (2008). Statistical Yearbook of Bangladesh, Ministry of Planning, Government of Bangladesh.
BBS (Bangladesh Bureau of Statistics) (2012). Statistical Yearbook of Bangladesh, Ministry of Planning, Government of Bangladesh.

Dasgupta S, Meisner C, Huq M (2006). Health effects and pesticide perception as determinants of pesticide use: Evidence from Bangladesh. WPS3776, The World Bank. 
Hanif MA (2000). Comparative Analysis Between FFS and Non-FFSs Farmers Environment Awareness. MS Thesis, Department of Agriculture Extension Education, BAU, Mymensingh.

Hasan MR (2005). An Economic Analysis of Contract Farming for Production and Export of High Value Vegetables in Bangladesh, MS Thesis, Department of Agricultural Economics, Bangladesh Agricultural University, Mymensingh.

Hossain MM (1999). Farmers Perception of the Effect of Agro-chimecalsc con Environment. MS Thesis, Department of Agriculture Extension Education, BAU, Mymensingh.

Howard PH, Boethling RS, Jarvis WF, Meylan WM, Michalenko EM(1991). Handbook of Environmental Degradation Rates. Lewis Publishers, Ann Arbor, Michigan, USA.

Islam MM, Motiur B, Akanda MGR (1998). Farmers awareness on the environmental Pollution. Bangladesh Journal of Trading and Development, 11(1 \&2): 33-38.
Matthews GA (2006). Pesticides: Health, Safety and the Environment. Blackwell Publishing, Oxford. UK

Mullen JD (1995). Estimating environmental and human health benefits of reducing pesticide use, through integrated pest management programs. MSc Thesis, Virginia Polytechnic Institute and State University, Blacksburg, Virginia, USA.

Sarkar RC (1999). Farmer perception regarding environmental degradation due to the use of agrochemicals. Unpublished MS Thesis, Department of Agriculture Extension Education, BAU, Mymensingh.

Singh B, Gupta MK (2009). Pattern of use of personal protective equipment and measures during application of pesticides by agricultural workers in a rural area of Ahmednagar district. India, Indian J Occup \& Env Med.,13 (3): 127130.

Sutradhar NC (2002). Farmers awareness on environmental degradation caused by the use of modern agricultural technologies. MS Thesis, Department of Agriculture Extension Education, BAU, Mymensingh. 